\title{
QUALITY ASSESSMENT OF REPRODUCTIVE AND CHILD HEALTH SERVICES IN KAMRUP DISTRICT OF ASSAM
}

\author{
Alpana Priya Rabha1, Jutika Ojah², Anjanamoyee Saikia ${ }^{3}$ \\ ${ }^{1}$ Assistant Professor. Department of Community Medicine, AMC, Dibrugarh. \\ ${ }^{2}$ Professor \& HOD, Department of Community Medicine, GMC, Guwahati. \\ ${ }^{3}$ Lecturer (Statistic), Department of Community Medicine, GMC, Guwahati.
}

\begin{abstract}
BACKGROUND

The provision of good quality care is the main thrust of the RCH programme. Greater emphasis is given to better quality of services as compared to the previous National Family Planning Programme.

Objectives- 1) To assess the quality of RCH services, 2) To assess the client's satisfaction level availing the RCH services provided by the health professionals, 3) To make recommendations based on findings of the studies.
\end{abstract}

\section{MATERIALS AND METHODS}

The study was conducted in 3 CHCs, 5 PHCs and 10 S/Cs randomly selected in Kamrup District of Assam during August 07 -July 08. The study instruments were a) quality assessment checklists for CHC/PHC and also for S/Cs and exit interview with the clients availing the RCH Services. The data was collected from records, interviews of the health personnel and the clients availing the RCH services and lastly by observation method.

\section{RESULTS}

The quality of reproductive and child health services was assessed by three dimension of quality requiring measurement using a system approach-inputs, process and outputs.

\section{CONCLUSION}

The quality of RCH services was found to be better at CHCs than the PHCs.

\section{KEYWORDS}

Quality of Care, Reproductive Health, Quality Assessment, Quality Assurance, Quality.

HOW TO CITE THIS ARTICLE: Rabha AP, Ojah J, Saikia A. Quality assessment of reproductive and child health services in Kamrup district of Assam. J. Evolution Med. Dent. Sci. 2017;6(62):4543-4546, DOI: 10.14260/Jemds/2017/983

\footnotetext{
BACKGROUND

Reproductive health is an important part of human life. It is crucial \& central to human health. Reproductive health affects the lives of women or men conception to birth through adolescence to old age or includes the attainment or maintenance of good health as well as the prevention or treatment of ill health.

Reproductive health implies that every woman has the sight of access to appropriate care services that enables her to plan or go safely through pregnancy or child birth.

Over $1 / 3^{\text {rd }}$ of all deaths among adult women in the developing world are due to reproductive health problems, as compared to same $12 \%$ in men. Pregnancy in not a disease yet, pregnancy related deaths constitute the leading cause of healthy life lost among women of reproductive age (in SEAR).

Public health activities are concerned with the wellbeing of all people irrespective of age, sex or other characteristics. In India women in child bearing age (15-49) group constitute

Financial or Other, Competing Interest: None.

Submission 15-06-2017, Peer Review 09-07-2017,

Acceptance 15-07-2017, Published 03-08-2017.

Corresponding Author:

Dr. Alpana Priya Rabha,

Assistant Professor

Department of Community Medicine,

Assam Medical College,

Dibrugarh, Assam.

E-mail: alporabha@gmail.com

DOI: $10.14260 /$ jemds $/ 2017 / 983$

$21.7 \%$ or children under 15 years of age $39.3 \%$ of the total population. Investment in women's health is new recognised as an essential component of social and economic growth. Quality of care was perceived as an integral component of peoples' reproductive rights. Concept of quality assurance or quality of care was not explicitly mentioned in the 1978 Alma Ata Declaration. The Primary Health Care approach provides a key route to achieve affordable universal coverage for all. But quality assurance is critical to the success of the goal of health for all.

Quality assurance in the broad sense encompasses the issues of technical performances, effectiveness of care, efficiency of service delivery, accessibility, interpersonal relations, continuity of services, choice of providers and treatment and physical infrastructure and comfort. Responsiveness which is one of the three intrinsic goals of a health system, could also be regarded as a measure of a quality of care. Quality is defined by Institute of Medicine as "the extent of which health services for individual and population increases the likelihood of desired health outcomes and are consistent with current professional knowledge. Quality assessment determines the extent to which actual practice is consistent with a particular indicator of quality, such as adherence to practice guidelines. The NRHM launched since 2005 primarily aims to improve access of the rural population to equitable, affordable, and quality health care.

According to the conceptual framework, proposed by Donabedian, the present study has been proposed to be 
carried out in Kamrup district to assess the quality of reproductive and child health services at Primary and Secondary level and to identify the weakness so that the appropriate measures may be taken to provide responsive and effective care to each mother and every child.

\section{MATERIALS AND METHOD:}

This cross-sectional study was undertaken during August 07July 08, in the CHCs, PHCs and S/Cs of Kamrup (Rural) district of Assam. From the total no. of 9 CHCs and 12 PHCs, 30\% of CHCs and $40 \%$ of PHCs had been selected randomly for the study. From each PHCs 2 S/C s had been selected randomly based on their distance from the PHC, one within 5 kilometres and the other situated more than the 5 kilometres from the selected PHCs. Thus, a total no 3 CHCs and 5 PHCs and $10 \mathrm{~S} / \mathrm{Cs}$ were selected for the study. The data had been collected by periodic visits to the selected health facilities (CHCs, PHCs and S/Cs). The information were collected from those facilities by using input from records, interviews of the health personnel (MO, ANM/LHV, Lab. Tech, etc.) and the clients availing the RCH services and observation methods. In this study, for the clients satisfaction level had been assessed by exit interview on the basis of 12 points scale and scoring system for the positive response. Based on the number of positive responses, services were categorised as very good, good, average and poor; and graded as A-very good (10-12), B-good (7-9), C-average (4-6), D-(poor). The objects comprised of clients availing RCH services which included antenatal visits, mothers having 0-5 years of children and women in reproductive age group coming to CHCs and PHCs. Client's satisfaction was assessed in the following service areas- antenatal services, child health services including ARI, diarrhoea and immunisation, family planning services and RTI/STI services in CHCs and PHCs. The data had been collected by exit interview in the OPDs using pretested and predesigned structured schedule. Two clients were interviewed for each of the health facility. Thus, a total 96 clients were interviewed for client satisfaction.

\section{Statistical Analysis}

The statistical analysis was carried out manually. The data were presented in forms of diagrams wherever applicable.

\section{RESULTS}

\begin{tabular}{|c|c|c|}
\hline Manpower or Staff & No. of CHC (n=3) & \% \\
\hline Specialists-OB/GYN & 2 & 66.66 \\
\hline Paediatrician & 2 & 66.66 \\
\hline Physician & 1 & 33.33 \\
\hline Surgeon & 0 & 0 \\
\hline MOs---MBBS & 3 & 100 \\
\hline Staff Nurse---GNM & 3 & 100 \\
\hline Pharmacist/Compounder & 3 & 100 \\
\hline Laboratory Technician & 3 & 100 \\
\hline \multicolumn{2}{|c|}{ Table 1. Distribution of Manpower } \\
at the Community Health Centre \\
\hline
\end{tabular}

In this study, $\mathrm{OB} / \mathrm{GYN}$ and paediatricians were available only $66.66 \%$ CHCs. The others mainly MOs, staff nurse, pharmacists and Lab technicians were available in all the CHCs. None of CHCs had a general surgeon.

\begin{tabular}{|c|c|c|c|c|}
\hline \multirow{2}{*}{$\begin{array}{c}\text { Availability of } \\
\text { Equipment \& Supplies }\end{array}$} & \multicolumn{2}{|c|}{ CHC $(n=3)$} & \multicolumn{2}{|c|}{ BPHC $(n=5)$} \\
\hline & No & $\%$ & No & $\%$ \\
\hline BP apparatus \& stethoscope & 3 & 100 & 5 & 100 \\
\hline $\begin{array}{l}\text { Adult \& infant weighing } \\
\text { machine }\end{array}$ & 3 & 100 & 5 & 100 \\
\hline $\begin{array}{l}\text { Autoclave/boiler in working } \\
\text { condition }\end{array}$ & 2 & 66.66 & 3 & 60 \\
\hline Complete DDKs/delivery kits & 3 & 100 & 5 & 100 \\
\hline Sterile MVA syringe & 2 & 66.66 & 0 & 0 \\
\hline Functional EVA available & 0 & 0 & 0 & 0 \\
\hline Paediatric resuscitation kits & 3 & 100 & 5 & 100 \\
\hline Suction apparatus & 3 & 100 & 3 & 60 \\
\hline $\begin{array}{l}\text { Oxygen cylinder with tubing } \\
\text { wrench \& disposable masks }\end{array}$ & 3 & 100 & 2 & 40 \\
\hline $\begin{array}{c}\text { Sufficient no. of syringes \& } \\
\text { needles }\end{array}$ & 3 & 100 & 5 & 100 \\
\hline Sterile suturing tray & 3 & 100 & 5 & 100 \\
\hline $\begin{array}{l}\text { Table 2. Showing Dist } \\
\text { of Equipment and Sup }\end{array}$ & 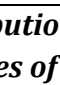 & $f A v$ & & \\
\hline
\end{tabular}

Table no. 2 showed that the BP apparatus \& stethoscope, adult and infant weighing machine, complete DDK, paediatric resuscitation kits, suction apparatus, oxygen cylinder with tubing wrench \& disposable masks, syringes \& needles and sterile suturing trays were available in all the CHCs. But the autoclave/boiler were available in only $66.66 \%$ CHCs and $60 \%$ PHCs. The sterile MVA syringes were available only $66.66 \%$ CHCs and none of the health care facilities had the available functional EVA. The oxygen cylinders were available only $40 \%$ of BPHCs.

\begin{tabular}{|c|c|c|c|c|}
\hline Availability of Essential & \multicolumn{2}{|c|}{ CHC (n=3) } & \multicolumn{2}{|c|}{ BPHC (n=5) } \\
\cline { 2 - 5 } Drugs and Supplies & No & \% & No & \% \\
\hline Maternal health & 3 & 100 & 5 & 100 \\
\hline Child health & 3 & 100 & 3 & 60 \\
\hline Drugs for EmOC & 3 & 100 & 4 & 80 \\
\hline Emergency drugs & 2 & 66.66 & 2 & 40 \\
\hline Essential drugs for RTI/STIs & 3 & 100 & 4 & 80 \\
\hline \multicolumn{6}{|c|}{ F P supplies } & 3 & 100 & 5 & 100 \\
\hline Disinfection supplies & 1 & 33.33 & 0 & 0 \\
\hline Table 3. Distribution of CHC and BPHC According to the \\
Availability of Essential Drugs and Supplies \\
\hline
\end{tabular}

From the above table, it had been observed that the maternal health supplies were available in all the CHCs and PHCs. The drugs for EmOC and child health supplies were available in all the CHCs. $60 \%$ and $80 \%$ PHCs had the available drugs and supplies for the child health and EmOC. The emergency drugs were available in $66.66 \%$ and $40 \%$ of the CHCs and PHCs. The essential drugs for RTI/STI were available in all the CHCs and only $80 \%$ of the PHCs. The family planning supplies were available in all the CHCs and PHCs. The supplies for disinfection were available in only $33.33 \%$ of the CHCs. None of the PHCs had the available supplies for disinfection. 


\begin{tabular}{|c|c|c|}
\hline $\begin{array}{l}\text { Family Planning } \\
\text { Service Activities }\end{array}$ & $\begin{array}{c}\text { No. of } S / C \\
(n=10)\end{array}$ & $\begin{array}{c}\text { Total No } \\
(\%)\end{array}$ \\
\hline \multicolumn{3}{|l|}{ Providers knowledge- } \\
\hline About IUD insertion & 10 & $10(100)$ \\
\hline OCP knowledge & 10 & $10(100)$ \\
\hline $\begin{array}{l}\text { From which month, a breast } \\
\text { feeding mother can take OCPs }\end{array}$ & 10 & $10(100)$ \\
\hline About correct ECP knowledge & 2 & $2(20)$ \\
\hline $\begin{array}{l}\text { F P records (OCP usage \& new } \\
\text { acceptance) }\end{array}$ & 10 & $10(100)$ \\
\hline $\begin{array}{l}\text { IUD records (Insertion \& } \\
\text { removal in last } 3 \text { months) }\end{array}$ & 0 & 0 (nil) \\
\hline $\begin{array}{l}\text { F P counselling about } \\
\text { different F P methods }\end{array}$ & 10 & $10(100)$ \\
\hline $\begin{array}{l}\text { Clients counselled on } \\
\text { methods \& side effects }\end{array}$ & 10 & $10(100)$ \\
\hline \multicolumn{3}{|c|}{$\begin{array}{c}\text { Table 4. Observation of Family Planning } \\
\text { Service Process at the Sub-centre }\end{array}$} \\
\hline
\end{tabular}

The table showed that the knowledge regarding the usage of IUDs and OCPs among the health care workers were found to be satisfactory $(100 \%)$ at all the Sub-centres. The knowledge regarding the usage of ECPs was poor among the health care workers at all the Sub-centres. The records on OCP usages and new acceptance were well maintained by the health care providers at the Sub-centres.

None of the Sub-centres had the records of IUD insertion and removal. FP counselling regarding the information, methods, side effect \& complications was found to be satisfactory $(100 \%)$ in all the Sub-centres.

\section{DISCUSSION}

The present study was aimed in finding the quality of RCH services at the Community health centres and Primary health centres in Kamrup District of Assam. Following the methodology of Avedis Donabedian ${ }^{1}$ the quality of $\mathrm{RCH}$ services were observed under the three main categories as service input (structure), process and service output. The service inputs were comprised of presence of manpower/staff, providers availability (skilled/trained), physical infrastructure, availability of equipment and supplies, availability of essential drugs and supplies, availability of essential protocols. Service process involved the observation of the RCH services including maternal health care, newborn care, child health care, family planning services and RTI/ STI services.

Service output comprised of the satisfaction of clients availing RCH services availing at the health care facilities. It is unsatisfactory if the evaluation of quality improvement efforts are based on staff assessment, a real improvement in quality cannot take place unless patients' views are involved (Gazi-Al Quary and Dave Haran 1999) ${ }^{2}$ In the present study, the availability of Obstetrician and Gynaecologists was $66.66 \%$, Physicians was $33.33 \%$ at the CHCs. Anaesthetists were available only in $66.66 \%$ of the CHCs. None of the CHCs had available general surgeons in position. MOs as well as other supporting staff were available in all the CHCs.

According to the Facility survey (2003), it was reported that the specialists like OB-GYN (51\%), Paediatrician (54\%), the staff nurse (83\%), Pharmacist (81\%), and Lab. technician $(87 \%)$ were available in CHCs in India. The National Commission on Macroeconomics and Health Survey (2005) showed that in CHCs alone there is a shortfall of $62 \%$ sanctioned posts of specialists and of the remaining 38\% are lying vacant, exhausting staff due to overwork and resulting in compromising on the quality of care. Satpathy SK (2005) reported that the vacancy position of four specialists in CHCs range from $40-50 \%$ and that surgeons and obstetricians/gynaecologists without an anaesthetist are not in a position to deliver the required surgical interventions. There is an acute shortage of anaesthetists in the country. The present study shows that the specialists and MOs were available in all the PHCs. The Ayush and Homeopathy doctors were available in only $60 \%$ of the PHCs. The other supporting staff including staff nurse, pharmacist/compounder, and laboratory technician were available in all the BPHCs. According to the facility survey (2003), 48.2\% of PHCs were adequately equipped with the staff including MOs (M/F) and paramedical staff. According to National Commission of Macroeconomics \& Health report (2005), doctors were in short supply. India has a doctor-population ratio of 59.7 per physician for 100,000 population worse than most developed countries which have 200 \& more for every $1,00,000$ population. Kapilashrami MC (2005) stated that most PHCs and S/Cs are often located in areas, which are not easily accessible and are appallingly underequipped with drugs, laboratory facilities, transportation etc. Sathpathy SK (2005) reported about the criticism of the functioning of the PHCs in the country. Although the numbers of doctors are more than the requirement about 700 PHCs are without a doctor because of maldistribution, lack of basic amenities \& lack of incentives for working of the rural areas. India has an adverse nurse population/nurse doctor ratio as compared to other countries. Yet only an estimated $40 \%$ of registered nurses are active because of low recruitment, migration and dropouts due to poor working condition (NCMH report, 2005). Agarwal $\mathrm{K}$ et al (1994) reported that the ratios of various health care providers such as MOs, PHN, Health visitors, ANM, to populations were not fulfilling the Govt. Recommended ratios. In this study, there was $100 \%$ availability of $\mathrm{BP}$ instruments with stethoscope; infant \& adult weighing machine; autoclave/boiler for sterilisation purposes; complete delivery kits; suction apparatus and sufficient needles with syringes almost available in all the healthcare facilities. The essential drugs and supplies were available for maternal health care in 100\% CHCs, PHCs and S/Cs; child health $100 \%, 60 \%$ in PHCs, $80 \%$ in S/Cs; drugs for emergency in $66.66 \%$ in CHCs and $40 \%$ in PHCs etc. In these studies, it was observed that the maternal health care process was satisfactory except on LAM and breastfeeding counselling. The child health care as well as FP service process were found to be satisfactory. The perception of quality varies from person to person according to individual's knowledge, values and resources (Humberto de Moraes Novaes, 1993). Haldar D, Sarkar AP et al (2008) also reported that client satisfaction was reflected by their happy expression about general facility, doctor's satisfaction, superiority of their health system and also by consistent regular utilisation by majority. Similar findings also reported by BS Akoijam et al (2007) ${ }^{3}$ that most of the patients were satisfied with overall care received by the health care provider at the tertiary care hospital. Nandan D (2006) in their study in Lalitpur and Jhansi and Mishra S K also reported that the workers lack of credibility in the 
community. The reason for dissatisfaction among community for PHC doctor was lack of caring and sympathetic behaviour. Ramanathan following a qualitative study have also suggested low levels of dissatisfaction in the face of indifferent quality of services. Verma et ${ }^{4}$ al in a study conducted in four Indian states also found that the client satisfaction of quality of care had a significant effect on their acceptance.

Benarjee B $(2003)^{5}$ reported the main deficiency regarding days and timings of the availability of specific services in the facility and the location of different service outlets within the centre by the clients. Patra B et al $(2006)^{6}$ reported that the level of satisfaction found to be affected by certain factors such as gender, educational level of the clients/respondents. A study conducted in Egypt by Gadallah $M$ et al (2003) reported that the level of satisfaction with Primary health care services is not affected by gender and educational level. However, in the present study it may not be applicable. Bharadwaj N, Hasan SB et al (1995) reported in their study that only $7 \%$ were highly satisfied, $75.9 \%$ were moderately satisfied \& $17 \%$ with poor receptivity and cause was found to be ignorance, illiteracy of the clients. Nandan $\mathrm{D}^{7}$ had also stated that the most important cause for not utilising the services was the distance. Similar findings have also been mentioned in studies conducted on quality of care in other countries such as of Elshabrawy et al (1992) in rural areas of Riyadh (Saudi Arabia) who found that $40 \%$ of the respondents were dissatisfied with the health care services duo to various reasons such as long distance in one third of the cases, absence of speciality clinics (38\%), unsuitable working hours (19.4\%) and long waiting times.

\section{CONCLUSION}

The study concluded that the quality of RCH services was found to be better in CHCs than the PHCs.

\section{REFERENCES}

[1] Donabedian A. The definition of quality \& approaches to its assessment. Vol 1. Explorations in quality assessment \& monitoring. Health Administration Press 1980.

[2] Al Quatari G, Haran D. Determinants of users satisfaction with primary health care settings and services in Saudi Arabia. International Journal for Quality in Health care 1999;11(6):523-31.

[3] Akoijam BS, Kanjengbam S, Bishwalata R, et al. Patients satisfaction with hospital care in a referral institute in Manipur. IJPH 2007;51(4):240-3.

[4] Verma R, Prinja S. Over reporting of RCH services coverage and operational problems in health management information system at the sub-centre level. IJCM 2007;32(3):185-8.

[5] Banerjee B. A qualitative analysis of maternal \& child health services of an urban health care centre by assessing client perception in terms of awareness, satisfaction \& service utilization. IJCM 2003;28(4):153-6.

[6] Patro BK, Rakesh K, Goswami A, et al. Community perception and client satisfaction about the primary health care services in an urban resettlement colony of New Delhi. IJCM 2008;33(4):250-4.

[7] Jain M, Nandan D, Misra SK. Qualitative assessment of health seeking behaviour \& perceptions regarding quality of health care services among rural community of district Agra. IJCM 2006;31(3):140-4. 